\title{
Hepatitis B immunity status of healthcare workers in Lagos, Nigeria
}

\author{
Chima NJEMANZE ${ }^{1}$ and Osaro ERHABOR ${ }^{1 *}$ \\ ${ }^{l}$ Blood Sciences Department Royal Bolton NHS Foundation Trust Bolton, Lancashire, United Kingdom. \\ *Corresponding author, E-mail: n_osaro@yahoo.com ; Brazley Avenue, Bolton BL3 2LD, United Kingdom.
}

\begin{abstract}
Healthcare workers (HCWs) are at risk of acquiring and transmitting parenteral infections including Hepatitis B Virus (HBV). The aim of this study was to determine the Hepatitis B immunity level among categories of health workers in Lagos metropolis. We evaluated 104 healthcare workers consisting of 66 males and 38 females aged $18-45$ years, mean age $31.33 \pm 5.28$ years. Of the 104 subjects evaluated, $39(37.5 \%)$ had detectable anti HB-s (mean \pm SEM titre, $237.78 \pm 15.20 \mathrm{i} \mu / \mathrm{L}$ ) while $64(\%)$ had a titre of $<10 \mathrm{i} \mu / \mathrm{L}$. Among the 41 subjects who had prior 3 doses of hepatitis B immunization prior to testing, 39(95.1\%) had HB-S antibody titre $>10 \mathrm{i} \mu / \mathrm{L}$ while $2(4.9 \%)$ were potential non-responders with titre $<10 \mathrm{i} \mu / \mathrm{L}$. There was no statistically significant difference in antibody response based on gender ( $>$ > 0.05). All the subjects who were referred for testing as a pre-employment requirement and those who had accidental percutaneous and mucosal exposures to high risk patient's blood and body fluid had HB-S titre $<10 \mathrm{i} \mu / \mathrm{L}$ (mean \pm SEM titre $3.50 \pm 2.09 \mathrm{i} \mu / \mathrm{L}$ ). Hepatitis B immunity was significantly higher $\left(\chi^{2}=1.92\right)$ among subjects previously vaccinated against hepatitis $B$ virus. $(\mathrm{p}=0.01)$. This study indicates the grave risk particularly to HBV to which healthcare workers in Nigeria are exposed in the course of the work caring for patients. There is need to urgently address the issue of formulation of occupational health policy in Nigeria as well as provision of training on universal precaution, phlebotomy, modifying procedures that have high risk, developing institutional policy for handling of sharps and postexposure management of healthcare workers, universal provision of protective HBV vaccine as well as provision of post exposure prophylaxis for those accidentally exposed.
\end{abstract}

(C) 2009 International Formulae Group. All rights reserved

Keywords: Occupational exposure, healthcare worker, needle sticks injury, hepatitis B vaccination.

\section{INTRODUCTION}

Sharp injuries and other exposure to patient's blood carry a risk of transmission of blood borne infections including hepatitis B virus. Healthcare workers are at risk of acquiring hepatitis $B$ virus (HBV) occupationally through percutaneous or mucosal exposure to contaminated blood and body fluids. Protection of healthcare worker requires their immunization against hepatitis B virus. Hepatitis B immunisation, using plasma derived vaccine, is a safe and effective means of protecting against hepatitis B infection in individuals at risk particularly from occupational-related exposures (Jefferson et al., 2000; Kuruuzum et al., 2008). Current recommendations in most developed countries are for vaccination against HBV particularly in high risk groups including healthcare worker (United States Public Health Service, 2001; Vagholkar et al., 2008). However despite the long-standing recommendations for high risk groups vaccination, hepatitis $B$ vaccination remains 
unavailable to healthcare workers in most resource-limited settings in Sub-Saharan Africa and even when available, the coverage remains low (Sofola and Uti, 2008; Ibekwe et al., 2006). HBV vaccination status is very low among healthcare workers in Nigeria and the prevalence of needle stick injuries is high (Okeke et al., 2008). A recent survey among doctors and dentists in a tertiary health institution in Ibadan Nigeria indicated a high HBV prevalence and low hepatitis B immunity (Olubuyide et al., 1997). Prevalence of hepatitis B virus infection in Nigeria among the rural population groups is high and the risk of contamination of healthcare workers in the course of their work by HBV from exposure to patient's blood and body fluids is generally high (Jombo et al., 2005). Appropriate healthcare programmes targeting vaccination against $\mathrm{HBV}$ infection among healthcare workers are not available even in most tertiary health institution in Nigeria. The aim of this study was to determine the Hepatitis B immunity status of health workers in Lagos metropolis.

\section{MATERIALS AND METHODS}

Subjects for this study included 104 consecutively recruited HCWs; Doctors 28 (26.9\%), Nurses 44 (42.3\%), Biomedical scientists 22 (21.2\%) and Laboratory Technicians 10 (9.6\%) referred to Pathcare Laboratories Limited Lagos from hospital, laboratories and healthcare institution in Lagos metropolis for determination of their Hepatitis B immunity status. Pathcare Laboratories Limited is a limited liability company rendering quality diagnostic services in Lagos and other surrounding states in the Western part of Nigeria. The survey was conducted over a 12 month-period between January 2006 and December 2006. Referral were either as a pre-employment requirement 35 (33.7\%), following initial Hepatitis B immunization 41 (39.4\%) and following accidentally exposure to high-risk patient's blood or body fluids from needle stick injury or mucosal exposure 28 (26.9\%). Study population was made up of 38 females
(36.5\%) and 66 males (63.5\%) with mean age $31.33 \pm 5.28$ years. All subjects filled a questionnaire that included sociodemographic data, reason for referral for test, prior hepatitis vaccination, number of doses received and dates, mode of immunization and duration after $3^{\text {rd }}$ immunisation. The immunization course in the 41 subjects who had HBV vaccination prior to study was 3 doses each of $20 \mu \mathrm{g}$ of vaccine at zero, one and 6 months into the upper arm aiming at the deltoid muscle. Immune response to $\mathrm{HBV}$ vaccine was assessed by measuring antibody level after 6-8 weeks of completion of 3 doses. Hepatitis B surface antibody higher than $10 \mathrm{i} \mu / \mathrm{L}$ is generally taken to be protective. Informed consent was obtained from study participants. Each subjects had a sample of serum taken for both qualitative and quantitative hepatitis B surface antibody (antiHB-S). Hepatitis B surface antibody (anti-HBS) was assayed using the commercially available Enzyme Immunoassay (Abbott Laboratories, North Chicago, IL). The test is an in vitro enzyme immunoassay test for the detection of Hepatitis B antibody in human serum. Enzyme Immunoassay measurements of antibody levels $>10 \mathrm{i} \mu / \mathrm{L}$ were considered as positive immunity to $\mathrm{HBV}$ while antibody level $<10 \mathrm{i} \mu / \mathrm{L}$ was considered a negative response.

\section{Statistical analysis}

The analyses were carried out using the program "Statistical Package for Social Sciences" (SPSS Inc., Chicago, IL), version 9. Descriptive analysis percentages of categorical variables (gender, antibody titre level) were reported. Comparisons were assessed using mean and chi-square test. A p value of $<0.05$ was considered statistically significant.

\section{RESULTS AND DISCUSSION}

The study population consisted of 66 males and 38 females aged $18-45$ years, mean age $31.33 \pm 5.28$ years. Of the 104 subjects tested made up of 28 doctors, 44 nurses, 22 biomedical scientists and 10 laboratory 
technicians , 39 (37.5\%) had detectable antiHB-S (mean \pm SEM titre, $237.78 \pm 15.20$ $\mathrm{i} \mu / \mathrm{L})$ while $64(\%)$ had a titre of $<10 \mathrm{i} \mu / \mathrm{L}$. Thirty-nine of the forty-one subjects $(95.1 \%)$ who had prior 3 doses of hepatitis $\mathrm{B}$ immunization had HB-S antibody titre $>10$ $\mathrm{i} \mu / \mathrm{L}$ while $2 / 41$ (4.9\%) were potential nonresponders with titre $<10 \mathrm{i} \mu / \mathrm{L}$. There was no statistically significant difference in antibody response based on gender among subjects who had prior hepatitis $B$ vaccination prior to study ( $p>0.05)$. All of the subjects who were referred to as a pre-employment check and those who had accidental percutaneous and mucosal exposures to high risk patient's blood and body fluid had HB-S titre $<10 \mathrm{i} \mu / \mathrm{L}$ (mean \pm SEM titre $3.50 \pm 2.09 \mathrm{i} \mu / \mathrm{L})$. Table 1 shows the HBV immunity status of subjects based on the referral groups. Chi square analysis $\left(\chi^{2}=1.92\right)$ among subjects based on referral groups indicated that hepatitis B immunity was significantly higher among subjects previously vaccinated against hepatitis $B$ virus. $(\mathrm{p}=0.01)$.

\section{DISCUSSION}

Hepatitis B immunisation, using plasma derived vaccine is a safe and effective means of protecting against hepatitis B infection particularly in groups of individuals at risk. In this study we had investigated the hepatitis B serologic immune status of healthcare workers in a resource-limited setting in Nigeria. Out of the 104 healthcare workers tested, only an insignificant 39 $(37.5 \%)$ had detectable anti HB-S. Our observed prevalence of a low hepatitis B serologic immunity among healthcare workers is consistent with previous reports in Nigeria (Adegboye et al., 1994; Olubuyide et al., 1997; Jombo et al, 2005; Ibekwe et al., 2006; Sofola and Uti, 2008) which indicated low hepatitis B immunity, a high rates of needle stick injuries and low vaccination coverage. Previous studies in other developing countries; Kenya (Suckling et al., 2006), Egypt (Talaat et al., 2003), Pakistan (Zeeshan et al., 2007) and Dominican Republic (Moro et al., 2007) all indicated a low level of hepatitis $\mathrm{B}$ vaccination and lack of post exposure prophylaxis among health workers. However report from studies in developed countries show a significantly higher immunity status and high vaccination uptake as well as availability of post exposure prophylaxis (Jefferson et al., 2000; Kuruuzum et al., 2008; United States Public Health Service, 2001; Vagholkar et al., 2008).

The lower prevalence of hepatitis B serologic immunity among health workers in Nigeria compared to healthcare workers in other developed countries may be due to the

Table 1: Immunity status to hepatitis B virus among the referral groups.

\begin{tabular}{|c|c|c|c|c|c|}
\hline $\begin{array}{l}\text { Referral } \\
\text { groups }\end{array}$ & $\begin{array}{l}\mathrm{N}(\%) \\
\text { tested }\end{array}$ & $\begin{array}{l}\mathrm{N}(\%) \\
\text { immunised }\end{array}$ & $\begin{array}{l}\text { N (\%) non- } \\
\text { immunised }\end{array}$ & $\chi^{2}$ & p-level * \\
\hline $\begin{array}{l}\text { Post } 3 \text { dose } \\
\text { vaccination }\end{array}$ & $41(39.4)$ & $39(95.1)$ & $2(4.9)$ & 1.92 & $* 0.01$ \\
\hline $\begin{array}{l}\text { Pre- } \\
\text { employment } \\
\text { check }\end{array}$ & $35(33.7)$ & $0(0)$ & 35 (100) & & \\
\hline $\begin{array}{l}\text { Post- } \\
\text { percutaneous } \\
\text { and mucosal } \\
\text { exposure }\end{array}$ & $28(26.9)$ & $0(0)$ & $28(100)$ & & \\
\hline
\end{tabular}


absence of established occupational health policy and policy for minimising the risk and management of percutaneous and mucosal exposure to high risk patient's blood and body fluids. Current recommendations in most developed countries are for vaccination of healthcare workers against HBV (Moloughney, 2001; United States Public Health Service, 2001; Pruss-Ustun et al., 2005; Vagholkar et al., 2008). Many medical and dental schools in England and other developed countries have been vaccinating students against hepatitis B on entry for some considerable time. The aim of this policy is to effectively ensure that most students are already immunised before commencing their studies and those at risk of transmitting infection are encouraged to pursue an alternative career. Most hospitals in Nigeria lack an operational occupational health policy. An Occupational Health Policy/Service is supposed to be an integral part of a hospital's commitment to her workforce. An Occupational Health Service is supposed to plan a comprehensive program to improve the health, safety and productivity of employees .The service should ideally focus on prevention and early intervention-tailored medical program that fits the hospital's staff specific needs at your workplace. Occupational Health Services should include; injury care and prevention, pre-employment physicals and medical examination to include protective immunization, management of sharps, provision and management of post exposure prophylaxis, fitness for duty checks, return to work check after sick leave as well as health and productivity services. The absence of occupational health policy and policy for management of sharps/occupational exposures in most hospitals in Nigeria brings to focus the risk faced by healthcare workers to HBV.

Among the 41 subjects that completed 3 doses of hepatitis B vaccination, 39 (95.1\%) had serologic immunity to HBV indicating a non response rate of $4.9 \%$. This observation is consistent with report from previous study which observed $95 \%$ serologic immunity to
HBV among 1067 healthcare worker tested in Australia (Vagholkar et al., 2008) and 71\% among 109 healthcare workers tested in the US (Craig et al., 1999). The high response rate observed among vaccinated subjects in our study may be due to the fact that the vaccines were injected into the upper arm aiming for the deltoid muscle. Previous reports had shown lower response rates in healthcare workers who had hepatitis B vaccine injected into their buttock (Puvacic et al., 2005; Chen and Gluud, 2000). Non serologic response following initial HBV vaccination has been attributed to early loss of antibody (Hollinger et al., 1996). The WHO advisory committee on immunization practices recommends that post vaccination testing be performed within 1 month to 2 months in persons at occupational risk (Immunization Practices Advisory Committee, 1991). In the United Kingdom, post vaccination testing for anti HB-s and routine boosting are performed based on the assumption that anti HB-S correlates with protection. This assumption is consistent with report by McIntyre (1995) which indicated that optimum protection of healthcare workers requires that anti HB-S is documented post vaccination. We suggest that post vaccination titres be checked and that healthcare workers with undetectable anti HB-S titres after vaccination be offered a booster dose of vaccine.

All the subjects who were tested as a pre-employment requirement as well as those who referred for testing because they were accidentally exposed percutaneous/mucosal to high risk patient's blood and body fluid had no serologic immunity to HBV. The risk of lacking protective antibody levels among healthcare workers in Nigeria rendering exposure prone procedures are grave. These healthcare workers not only have an elevated risk of acquiring infection but also of transmitting parenteral infections including HBV to patients. In most developed countries, when staffs are exposed to patient's blood, the occupational health unit attempts to test the source patient for hepatitis B surface antigen and antibodies for $\mathrm{HIV}$ and $\mathrm{HCV}$ after 
counselling and consent has been obtained. Staffs are encouraged to report incidents to their occupational health department which contacts the clinical team managing the source patient to approach the patient for test. Staffs not immuned to hepatitis $\mathrm{B}$ are giving hepatitis B immunoglobulin (Zhang et al., 2009). Hospitals in Nigeria as well as other resource limited settings in Africa could implement similar policies with the aim of protecting their $\mathrm{HCW}$ who become accidentally exposed to patient's blood and body fluid.

\section{Conclusion}

Hepatitis B virus (HBV) infection is preventable. Yet many healthcare workers in Nigeria and other resource-poor countries remain at risk. There is need to urgently address the issue of formulation of occupational health policy in Nigeria as well as provision of training on universal precaution, phlebotomy, modifying procedures that have high risk, developing institutional policy for handling of sharps and post-exposure management of healthcare workers, provision of protective HBV vaccine for all HCWs coupled with the provision of post-exposure prophylaxis for exposed healthcare workers.

\section{REFERENCES}

Adegboye AA, Moss GB, Soyinka F, Kreiss JK. 1994. The epidemiology of needlestick and sharp instrument accidents in a Nigeria hospital. Infec Control Hosp Epidemiol, 15(1): 27-31.

Craig B, Mitchell IC, Anthony JD, Joseph M, Melvin LA. 1999. Serologic Hepatitis B Immunity in Vaccinated Healthcare Workers. Arch Intern Med, 159: 14811483.

Chen W, Gluud C. 2000. Vaccines for preventing hepatitis $\mathrm{B}$ in healthcare workers. Cochrane Database Syst Rev, 2: CD000100.

Hollinger FB. 1996. Comprehensive control (or elimination) of hepatitis B virus transmission in the United States. Gut., 38(2): S24-S30.
Immunization Practices Advisory Committee. 1991. Hepatitis B virus: a comprehensive strategy for eliminating transmission in the United States through universal childhood vaccination. MMWR Morb Mortal Wkly Rep, 40(RR-13): 1-25.

Ibekwe RC, Ibeziako N. 2006.Hepatitis B vaccination status among healthcare workers in Enugu, Nigeria. Niger J Clin Prac, 9(1): 7-10.

Jefferson T, Demicheli V, Deeks J, MacMillan A, Sassi F, Pratt M. 2000. Vaccines for preventing hepatitis Bin health workers. Cochrane Database Syst Rev, 2: CD000100.

United States Public Health Service. 2001. Updated U.S. Public Service Guidelines for the management of the Management of Occupational Exposures to $\mathrm{HBV}$, $\mathrm{HCV}$, and HIV and Recommendations for Post exposure Prophylaxis. MMWR Recomm Rep, 50(RR-11): 1-52.

Jombo GT, Egah DZ, Banwat EB. 2005. Hepatitis B virus infection in a rural settlement of Northern Nigeria. Niger $J$ Med, 14(4): 425-428.

Kuruuzum Z, Yapar N, Avkan-Oguz V, Aslan H, Ozbek OA, Cakir N, Yuce A. 2008. Risk of infection in healthcare workers following occupational exposure to a non-infectious or unknown source. J Infec Control, 36(10): 27-31.

McIntyre PG. 1995. Hepatitis B vaccination follow-up. Lancet, 345: 1575.

Moloughney BW. 2004. Transmission and post exposure management of blood borne virus infections in the healthcare setting: where are we now? CMAJ, 154(4): 445-451.

Moro PL, Moore A, Balcacer P, Montero A, Diaz D, Gomez V, Garib Z, Weniger BG. 2007. Epidemiology of needlesticks and other sharps injuries and injection safety practices in the Dominican Republic. Am J Infec Control, 35(8): 552-559.

Okeke EN, Ladep NG, Agaba EI, Malu AO. 2008. Hepatitis B vaccination status and needle stick injuries among medical 
students in a Nigerian university. $J$ Med, 17(3): 330-332.

Olubuyide IO, Ola SO, Aliyu B, Dosumu OO, Arotiba JT, Olaleye OA, Odaibo GN, Odemuyiwa SO, Olawuyi F. 1997. Prevalence and epidemiological characteristics of hepatitis B and C infections among doctors and dentists in Nigeria. East Afr Med J, 74(6): 357-361.

Pruss-Ustun A, Rapiti E, Hutin Y. 2005. Estimation of the global burden of disease attributable to contaminated sharp injuries among healthcare workers. Am J Ind Med, 48(6): 482-490.

Puvacic S, Ravlija J, Puvacic Z, Curic I. 2005. Long term protection after hepatitis B vaccination. Bosn J Basic Med Sci, 5(3): 50-53.

Sofola OO, Uti OG. 2008. Hepatitis B virus infection and prevention in the dental clinic: Knowledge and factors determining vaccine uptake in a Nigerian dental hospital. Nig Q J Hosp Med, 18(3): 145-148.

Suckling RM, Taegtmeyer M, Nguku PM, AlAbri SS, Kibaru J, Chakaya JM, Tukei PM, Gilks CF. 2006. Susceptibility of healthcare workers in Kenya to hepatitis B: new strategies for facilitating vaccination uptake. J Hosp Infect, 64(3): 271-277.

Talaat M, Kandeel A, El-Shoubary W, Bodenschatz C, Khairy I, Oun S, Mahoney FJ. 2003. Occupational exposure to needlestick injuries and hepatitis $\mathrm{B}$ vaccination converage among healthcare workers in Egypt. Am J Infec Control, 31(8): 469-474.

Vagholkar S, Ng J, Chan RC, Bunker JM, Zwar NA. 2008. Healthcare workers and immunity to infectious diseases. Aust NZJ Public Health, 32(4): 367-371.

Zeeshan M, Jabeen K, Ali AN, Ali AW, Faroogui SZ, Mehraj v, Zafar A.2007. Evaluation of immune response to hepatitis B vaccine in healthcare workers at a tertiary care hospital in Pakistan: an observational prospective study. $B M C$ Infec Dis, 25(7): 120.

Zhang M, Wang H, Miao J, Du X, Li T, Wu Z. 2009. Occupational exposure to blood and body fluids among healthcare workers in a general hospital in China. Am J Ind Med, 52(2): 89-98. 